\title{
Early hemodynamics and metabolic changes after total abdominal evisceration for experimental multivisceral transplantation ${ }^{1}$
}

\author{
Efeitos hemodinâmicos e metabólicos iniciais da evisceração abdominal total para transplante \\ multivisceral experimental.
}

\author{
Ruy J. Cruz JuniorI, Alejandra G. Garrido", Maurício Rocha e SilvaII \\ ${ }^{\text {I }}$ Assistant-Professor, Staff-Surgeon, Starzl Transplantation Institute - Liver, Intestinal and Multivisceral Transplant Services, University of Pittsburgh \\ Medical Center, PA, USA. \\ ${ }^{\text {II }}$ PhD, Department of Surgery, University of São Paulo School of Medicine (FMUSP), Brazil. \\ III Professor Emeritus, University of São Paulo School of Medicine (FMUSP), Brazil.
}

\begin{abstract}
Purpose: Multivisceral transplantation (MVTx) has been accepted as standard therapeutic modality for patients with short-bowel syndrome associated with irreversible liver failure. Even nowadays, experimental models of MVTx grounds high incidence of intraoperative or early recipient mortality. Despite the known deleterious effects of hepatosplanchnic exenteration the impact of this procedure on systemic hemodynamics and metabolism remains to be determined. Methods: Nine dogs $(20.1 \pm 0.5 \mathrm{~kg})$ were subjected to an en bloc resection of all abdominal organs including, stomach, duodenum, pancreas, liver, spleen, small bowel, and colon. A woven double velour vascular graft was interposed between the suprahepatic and infrahepatic vena cava. Systemic hemodynamic were evaluated through a Swan-Ganz catheter, ultrasonic flowprobes, and arterial lines. Systemic $\mathrm{O}_{2}$-derived variables, glucose, and lactate metabolism were analyzed throughout the experiment. Results: Complete abdominal exenteration was associated with significant reduction in cardiac output, and mean arterial pressure (57\% and $14 \%$, respectively). Two hours after reperfusion a significant reduction in arterial $\mathrm{pH}$ and glucose were also observed. Oxygen consumption remained unaltered during the first two hours of the experiment, with a significant increase of lactate levels $(1.4 \pm 0.3$ vs. $7.6 \pm 0.4, p<0.05)$. Three animals died before the 3 hours of reperfusion were completed. Total abdominal exenteration for MVTx in dogs is associated with early major hemodynamics, and metabolic changes. Conclusion: The deleterious hemodynamic alterations observed are probably related with the association of severe acidosis, hyperlactemia, hypoglycemia, and reduction of total circulating blood volume. Close hemodynamic and metabolic monitoring should be provided during experimental MVTx in order to promote an increase in successful rates of this complex and challenging procedure.
\end{abstract}

Key words: Hemodynamics. Transplantation. Regional blood flow. Physiopatology. Dogs.

\section{RESUMO}

Objetivo: O transplante multivisceral (MVTx) é preconizado como tratamento de escolha em pacientes com síndrome do intestine curto associado com falência hepática irreverssível. Modelos experimentais de MVTx apresentam altas taxas de mortalidade intra-operatória e nas primeiras horas apos a reperfusão. Apesar dos deletérios efeitos hemodinâmicos da exenteração abdominal, o impacto deste procedimento na perfusão e no metabolismo sistêmico ainda esta por ser determinado. Métodos: Nove cães $(20.1 \pm 0.5 \mathrm{~kg})$ foram submetidos a ressecção em bloco de todos os orgãos abdominais incluindo, estômago, duodeno, pancreas, fígado, baço, intestino delgado, e colon. Uma prótese vascular foi interposta entre a veia cava infra e supra-hepática. Efeitos hemodinâmicos foram avaliados por meio de um cateter de Swan-Ganz catheter e Doppler ultrassônico. As variáveis dependentes de oxigênio, e o metabolismo da glicose e lactato foram avaliados durante todo o experimento. Resultados: A evisceração abdominal esteve associada a uma redução significativa do débito cardiaco e da pressão arterial média (57\% and 14\%, respectivamente). Duas horas após a reconstrução vascular da veia cava inferior observou-se uma redução significativa do $\mathrm{pH}$ e da glicose arterial. O consumo de oxigênio se manteve inalterado nas primeiras duas horas do experimento, com um significativo aumento dos níveis séricos de lactato $(1.4 \pm 0.3 v s .7 .6 \pm 0.4, p<0.05)$. Três animais morreram antes de 180 minutos após a reperfusão. Conclusão: A evisceração abdominal total esteve associada com graves repercussões hemodinâmicas e metabólicas sistêmicas. Estas graves alterações hemodinâmicas estam associadas, provavelmente, a combinação de vários fatores incluindo: acidose metabólica, hiperlactemia, hipoglicemia e redução do volume de sangue circulante. A cuidadosa monitorização hemodinâmica e metabólica deve ser realizada durante o MVTx experimental com a finalidade de promover um aumento das taxas de sobrevida deste complexo procedimento.

Descritores: Hemodinâmica. Transplante. Fluxo Sanguíneo Regional. Fisiopatologia. Cães.

${ }^{1}$ Research performed at Research Division, Heart Institute (InCor), University of São Paulo School of Medicine (FMUSP), Brazil. 


\section{Introduction}

Multivisceral transplantation (MVTx) has been accepted as a standard therapeutic modality for patients with short-bowel syndrome associated with irreversible liver failure that no longer can be maintained on total parenteral nutrition ${ }^{1,2}$. In 1983 the first clinical case was reported in a 6-year-old girl who developed short gut syndrome after a swimming pool accident and was terminally ill from liver failure. Unfortunately, the child died of hemorrhage immediately after the procedure ${ }^{3}$. Clinical outcome has improved in recent years with an actuarial graft survival rate of $63 \%$ in the first year after transplant ${ }^{1,2}$. The significant improvement in the graft and patient survival is a result of better patient selection, refinement of surgical technique and novel immunosupression regiments.

Large animal models have played an important role in MVTx research. Several alternative surgical techniques as well as models to evaluate the ischemia reperfusion injury and new immunossupressive drugs have been used large animals ${ }^{4-6}$.

The exclusion of the recipient abdominal organs during MVTx has been associated with major hemodynamic and metabolic alterations. Alternative techniques such as partial abdominal exenteration or even preservation of all organs in the recipient's abdominal cavity have been described to reduce the severe hemodynamic derangements during experimental transplantation ${ }^{7-10}$. However, the resection of all hepatosplanchnic organs before graft implantation is still the most commonly used procedure.

The impact of total abdominal evisceration on systemic hemodynamics and oxygen metabolism remains to be determined. Therefore we have developed a model to evaluate the initial hemodynamic and metabolic changes associated with an en bloc resection of all abdominal organs including; stomach, duodenum, pancreas, liver, spleen, small bowel, and colon.

\section{Methods}

The study was performed using nine male dogs, weighing $20.1 \pm 0.5 \mathrm{~kg}$. The experimental protocol followed the "Principles of Laboratory Animal Care" formulated by the National Society for Medical Research, and the "Guide for the Care and Use of Animals" by the National Institutes of Health.

\section{Animal preparation}

The animals fasted for 12 hours before the study with free access to water. Anesthesia was induced with an intravenous injection of $0.1 \mathrm{mg} / \mathrm{kg}$ of morphine sulfate followed by $25 \mathrm{mg} / \mathrm{kg}$ of pentobarbital sodium. After endotracheal intubation, the animals were mechanically ventilated with an inspired oxygen fraction of 1.0. The ventilator was adjusted to achieve an initial arterial $\mathrm{pCO}_{2}$ between 35 and $45 \mathrm{mmHg}$. Additional doses of pentobarbital, $2 \mathrm{mg} / \mathrm{kg}$, were used as required. A urinary bladder catheter was placed for urinary drainage. We used a heating pad in the operating table to maintain normothermia throughout the experiment. All animals received 5\% dextrose in normal saline solution, at $20 \mathrm{ml} / \mathrm{Kg} / \mathrm{h}$ rate, to compensate fluid losses related to the surgical preparation.

The right carotid artery was dissected and a polyethylene cannula (P240) was introduced to measure mean arterial pressure and to collect arterial blood samples for blood gas, $\mathrm{pH}$, bicarbon- ate, base deficit, hematocrit, and hemoglobin analysis. A 7.5 Fr flow-directed thermodilution fiberoptic pulmonary artery catheter with thermal filament (CCOmbo 744H7.5F, Edwards Swan-Ganz, Baxter Edwards Critical Care, Irvine, CA, USA) was introduced through the right external jugular vein and its' tip placed in the pulmonary artery, guided by the pressure wave tracings. This catheter was connected to a cardiac computer (Vigilance, Baxter Edwards Critical Care, Irvine, CA, USA), to measure cardiac output, using $3-\mathrm{ml}$ bolus injections of isotonic saline at $20^{\circ} \mathrm{C}$ every thirty minutes. This catheter was also used to collect mixed venous blood samples for gas analysis. All pressure-measuring catheters were connected to pressure disposable transducers (Transpac Transducer, Abbott, Chicago, IL, USA) and then to a Biopac Data Acquisition System (Model MP100, Biopac Systems, Goleta, CA, USA) for continuous recording of systemic and pulmonary artery pressures. The abdomen was opened through a median celiotomy. The supra-celiac aorta was dissected and a transit time ultrasonic flowprobe (Transonic System Inc., Ithaca, NY, USA) was placed around this vessel and connected to a flowmeter (T206 Transonic Volume Flowmeter, Transonic Systems, Inc, Ithaca, NY, USA). The esophageal junction and the distal rectum were transected with a GIA stapler. The mesenteric and celiac arteries were dissected and encircled with umbilical tape (Figure 1A). All the ligaments connecting the abdominal organs (liver, pancreas, stomach, colon and spleen) and the abdominal wall were divided. The suprahepatic and infrahepatic inferior vena cava were dissected and encircled with umbilical tape. Blood samples from arterial and venous territories were analyzed immediately after their collection, by a Stat Profile Ultra Analyzer (Nova Biomedical, Waltham, MA, USA).

\section{Experimental design and total abdominal evisceration}

model

One hour after the surgical preparation was completed baseline measurements were obtained (BL). The mesenteric and celiac arteries were clamped and divided. The inferior vena cava above and below the liver were cross-clamped and transected. Organs including; the stomach, duodenum, pancreas, liver, small bowel, spleen, and colon were removed en bloc. A woven double velour vascular graft (Boston Scientific, Meadox Medical, Inc, Oakland, CA) was interposed between suprahepatic and infrahepatic IVC. The anastomoses were performed using running 5-0 prolene suture (Figure 1B). After the completion of the anastomosis the vascular clamps were removed and the animals observed for an additional 180 minutes. At the end of each experiment, the animals were euthanized by anesthesia overdose, followed by an intravenous injection of saturated potassium chloride.

\section{Measured variables}

Mean systemic and pulmonary arterial pressures, and aortic blood flow (AoBF) were continuously recorded. Intermittent cardiac output was measured every 30 minutes. Arterial and mixed venous base deficit, $\mathrm{pH}, \mathrm{pCO}_{2}, \mathrm{pO}_{2}$, oxygen saturation, hemoglobin, hematocrit, lactate and glucose were measured at baseline (BL), and then 30, 60, 120, and 180 minutes after reperfusion (R30, R60, R120, and R180, respectively). Systemic oxygen delivery, consumption and extraction ( $\mathrm{DO}_{2}$ syst, $\mathrm{VO}_{2}$ syst and $\mathrm{O}_{2}$ ERsyst) were calculated using standard formulae. 


\section{Statistical methodology}

Experimental data are presented as mean \pm standard error of the mean. Statistical analysis was performed using an analysis of variance and post hoc Tukey's test. Statistical significance was considered for $p$ values less than 0.05 .

\section{Results}

All animals were hemodynamically stable at the baseline measurement. After total abdominal evisceration a significant reduction in MAP, CO, AoBF, and $\mathrm{SvO}_{2}$ were observed (Table 1). The AoBF/CO presented a significant reduction after removal of the abdominal organs en bloc ( $48 \pm 5 \%$ to $15 \pm 1 \%)$. During reperfusion, a significant reduction in arterial $\mathrm{pH}$, hemoglobin, and glucose level was also observed (Table 1 and Figure 2).

A significant and progressive reduction of systemic oxygen delivery, with a concomitant increase of systemic oxygen extraction ratio, was observed after reperfusion (Figure 3). However, changes on systemic oxygen consumption were detected only 3 hours after the reperfusion (Figure 3). At the same time, we could observe a progressive increase in arterial lactate levels (Figure 2). Three animals died before the end of the experiment, at 125,130 , and 155 minutes after reperfusion. the supraceliac aorta.
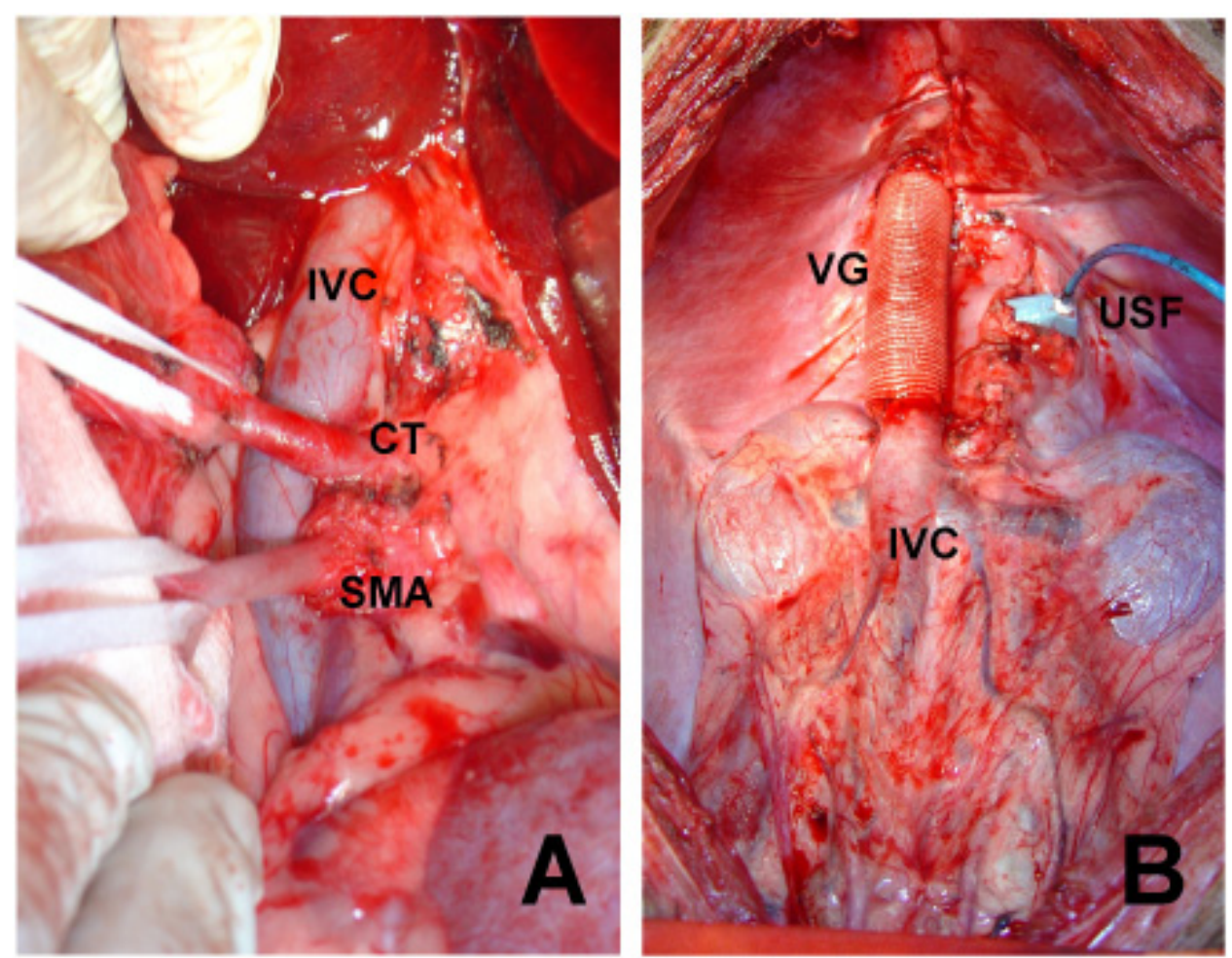

FIGURE 1 - (A) The celiac trunk and superior mesenteric artery (CT and SMA, respectively) were encircled with umbilical tape before total abdominal exenteration. (B) Final aspect after en bloc resection of all abdominal organs. The vascular graft (VG) is interposed between suprahepatic and infrahepatic inferior vena cava (IVC). The ultrasonic flowprobe (USFB) can be seen around

TABLE 1 - Mean arterial and pulmonary arterial pressures (MAP and MPAP), cardiac output (CO), aortic blood flow (AoBF), aortic blood flow/ cardiac output ratio $(\mathrm{AoBF} / \mathrm{CO})$ mixed venous oxygen saturation $\left(\mathrm{SvO}_{2}\right)$ and arterial hemoglobin and $\mathrm{pH}$; in the animals subjected to total abdominal evisceration $(\mathrm{n}=9)$.

\begin{tabular}{lccccc}
\hline & BL & T30 & T60 & T120 & T180 \\
\hline MAP $(m m H g)$ & $125.3 \pm 8.4$ & $112 \pm 7.7$ & $108.2 \pm 7.4^{a}$ & $76.8 \pm 10.1^{a}$ & $48.8 \pm 8.1^{a}$ \\
MPAP $(\mathrm{mmHg})$ & $19.8 \pm 1.2$ & $16.7 \pm 1.3$ & $16.1 \pm 1.6$ & $15.9 \pm 1.6$ & $13.6 \pm 0.9^{a}$ \\
$\mathrm{CO}(\mathrm{L} / \mathrm{min})$ & $2.14 \pm 0.32$ & $0.93 \pm 0.10^{a}$ & $0.91 \pm 0.14^{a}$ & $0.62 \pm 0.11^{a}$ & $0.48 \pm 0.06^{a}$ \\
$\mathrm{AoBF}(\mathrm{L} / \mathrm{min})$ & $1.06 \pm 0.13$ & $0.32 \pm 0.07^{a}$ & $0.26 \pm 0.04^{a}$ & $0.18 \pm 0.04^{a}$ & $0.11 \pm 0.02^{a}$ \\
$\mathrm{AoBF} / \mathrm{CO}(\%)$ & $48 \pm 5$ & $31 \pm 6$ & $28 \pm 4$ & $25 \pm 3$ & $15 \pm 1$ \\
$\mathrm{SvO}(\%)$ & $79.3 \pm 2.9$ & $70.8 \pm 5.1$ & $64.7 \pm 4.0^{a}$ & $54.2 \pm 5.1^{a}$ & $42.8 \pm 3.4^{a}$ \\
arterial $\mathrm{Hb}(\mathrm{g} / \mathrm{dl})$ & $13.8 \pm 0.8$ & $11.3 \pm 0.7^{a}$ & $11.5 \pm 0.7^{a}$ & $11.5 \pm 0.8^{a}$ & $10.9 \pm 0.5^{a}$ \\
arterial pH & $7.38 \pm 0.01$ & $7.32 \pm 0.01^{a}$ & $7.31 \pm 0.02^{a}$ & $7.26 \pm 0.02^{a}$ & $7.23 \pm 0.03^{a}$ \\
\hline
\end{tabular}

Legends: Baseline (BL), and 30, 60, 120 and 180 minutes after reperfusion (R30, R60, R120 and R180, respectively). Data are presented as mean \pm standard error of the mean. ${ }^{a} p<0.05 v s$. baseline. 


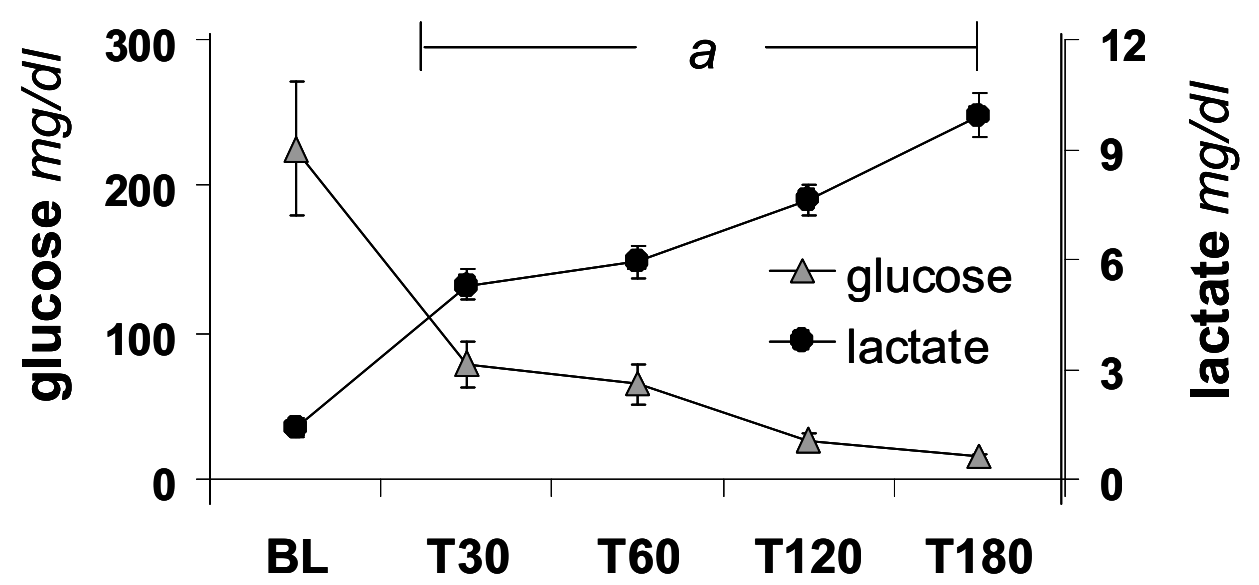

FIGURE 2 - Lactate and glucose levels, during the baseline (BL) and 30, 60, 120 and 180 minutes after reperfusion (R30, R60, R120 and R180, respectively). Data are presented as mean \pm standard error of the mean. a $p<0.05$ versus baseline.
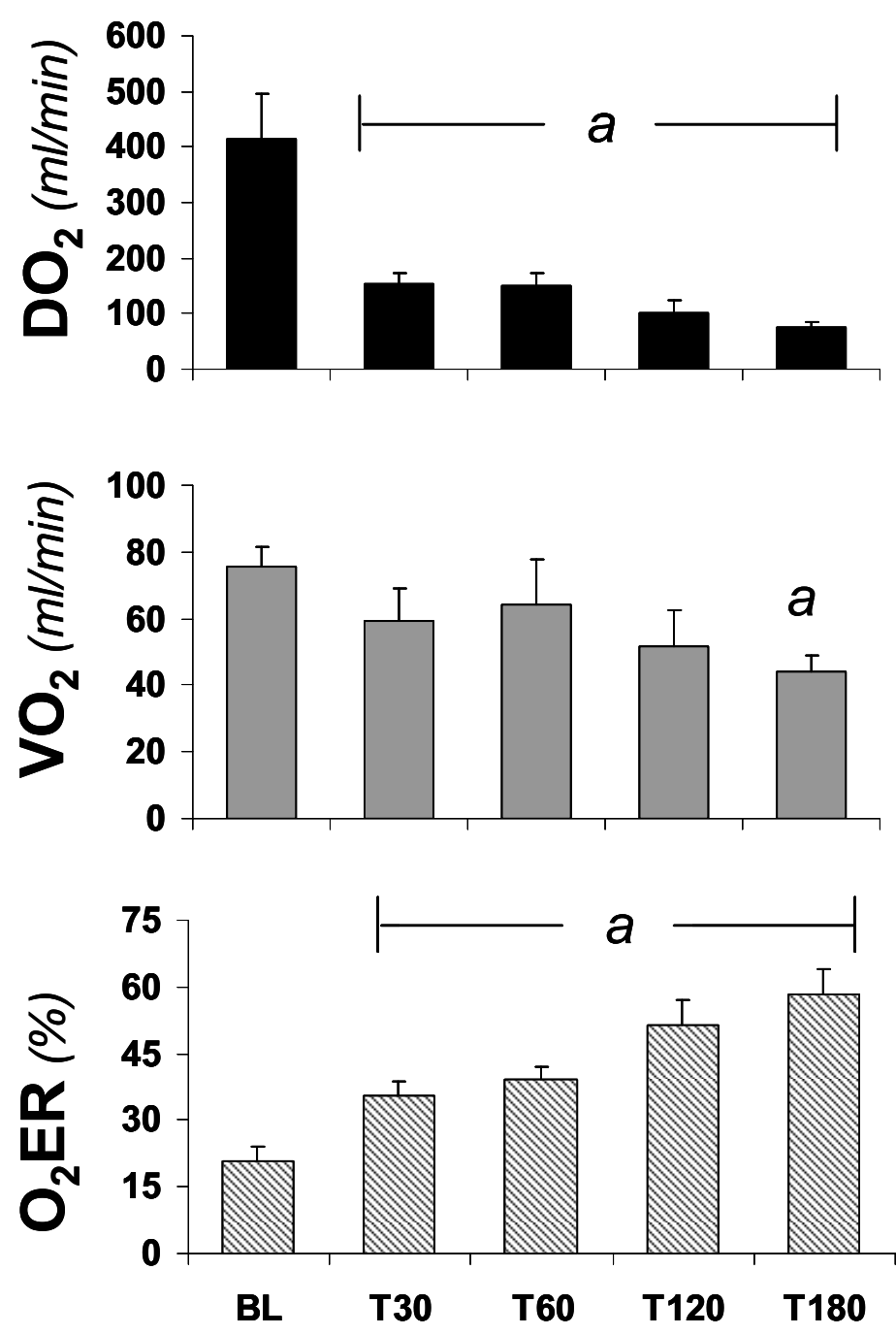

FIGURE 3 - Systemic oxygen delivery, consumption and extraction ratio (DO2, VO2 and O2ER, respectively), during the baseline (BL) and 30, 60, 120 and 180 minutes after reperfusion (R30, R60, R120 and R180, respectively). Data are presented as mean \pm standard error of the mean. $a$ $p<0.05$ versus baseline.

\section{Discussion}

In the present study, we were able to show a rapid and progressive deterioration of systemic hemodynamic after complete abdominal evisceration in dogs. We also demonstrated a significant impairment of oxygen, glucose, and lactate metabolism after removal of hepatosplanchnic organs.

Initial experimental MVTx were performed by Starzl and Kaupp in the 1960's with many intraoperative failures and the longest survival rate being 9 days ${ }^{11}$. Even nowadays, experimental models of MVTx grounds high incidence of intraoperative or early recipient mortality. The cause of death was mainly due to bleeding and/or major hemodynamic and metabolic alterations caused by exclusion of recipient abdominal organs $\mathrm{s}^{4,5,10}$. Despite these known deleterious effects of hepatosplanchnic exenteration for MVTx, this is the first study evaluating the hemodynamic and metabolic effects of this procedure in a large animal model.

The total abdominal exenteration was associated with a significant decrease in CO and MAP (57\% and 14\% of baseline values, respectively) one hour after the reperfusion. We can speculate three different hypotheses to explain the observed systemic hemodynamic changes.

First, considering that splanchnic territory receives almost $30 \%$ of the total cardiac output, it seems reasonable to admit that exenteration of all splanchnic organs could be associated with a significant reduction of total blood volume ${ }^{12}$. The reduction of intravascular compartment is associated with a significant reduction in cardiac pre-load, stroke volume, and cardiac output as observed in our experiment. Second, several studies have shown that hypoglycemia is associated with increased risk of cardiac dysfunction, and/or arrhythmias ${ }^{13}$. Third, metabolic acidosis and hyperlactemia are well known potent cardiac depressors, and could be lead to a significant hemodynamic disturbance. Teplinsky et al. have demonstrated in a canine model of lactic acidosis (trough a continuous intravenous infusion of $0.5 \mathrm{~N}$ lactic acid), a significant impairment in the left ventricular contractility with a reduction 
of $40 \%$ in stroke volume ${ }^{14}$. Therefore, the combination of these three factors could be contributed to the rapid hemodynamic deterioration after total abdominal evisceration.

We were also able to detect peculiar blood flow redistribution after total abdominal exenteration, with an increase of $32 \%$ in cardiac output fraction to the head and anterior extremities (Table 1). This phenomenon is similar to other shock states (septic or hemorrhagic shock) in which cerebral blood flow needs to be maintained in detriment of perfusion in other territories ${ }^{15-17}$. Hence, the "exclusion" of splanchnic circulation could have led to blood flow redistribution preferable to the cerebral and coronary circulation.

Several experimental studies have demonstrated the hemodynamic and metabolic alterations after total hepatectomy as an initial step of liver transplantation or as a model of fulminant hepatic failure ${ }^{18-20}$. Total hepatectomy induces a progressive and slow deterioration of systemic hemodynamics. After total hepatectomy a significant increase of ammonia and lactate levels, with a survival time being up to 17 hours is also observed ${ }^{18}$. It should be noted, that only 6 out of 9 animals were alive 3 hours after abdominal evisceration. This poor survival rate demonstrated a more severe hemodynamic and metabolic dearengement associated with complete abdominal evisceration when compared with total hepatectomy alone.

As mentioned above, a significant reduction of cardiac output by approximately $60 \%$ of baseline was observed $30 \mathrm{~min}$ after abdominal exenteration. The reduction of $\mathrm{CO}$ at these levels was associated with a significant reduction in systemic oxygen delivery $\left(\mathrm{DO}_{2}\right)$. However, oxygen consumption was maintained at baseline values during the first two hours of reperfusion through an increase in the oxygen extraction ratio. These findings suggest that the critical $\mathrm{DO}_{2}$ level needed to jeopardize systemic $\mathrm{VO}_{2}$ and activate anaerobic metabolism (i.e. oxygen supply/demand mismatch) was not reached during this period ${ }^{15}$. However, we could observe a progressive and sustained increase in plasma lactate levels after complete abdominal evisceration (Table 1). During shock, lactate is produced from pyruvate in order to maintain anaerobic glycolysis with low energy production ${ }^{15,18}$. In the present experiment however, lactate cannot be analyzed as a marker of ischemia or oxygen metabolism imbalance. The increase in the levels of this metabolite suggests the possible association of increased production and most importantly, failure of hepatic clearance of peripherally generated lactate.

There was an abrupt reduction of glucose levels two hours after total abdominal exenteration $(225 \pm 54 \mathrm{mg} / \mathrm{dl}$ to $28 \pm 4 \mathrm{mg} / \mathrm{dl})$. Previously, Lauritsen et al have demonstrated a significant decrease of glucose levels in hepatectomised pigs despite significant renal gluconeogenesis. In the same study, no significant release of glucose was found from gut or muscles ${ }^{21}$. In humans the glucose homeostasis is different, with no significant changes in glucose levels during anhepatic phase of liver transplantation. The rate of glucose production by the kidney in humans and dogs are similar ranging from 10 to $30 \%$ of whole body glucose released, keeping the glucose metabolism homeostasis during liver transplantation ${ }^{21-24}$. Therefore, we should expect normal glycemia after complete abdominal evisceration in dogs. However, it should be noticed that the abdominal exenteration (including pancreas) could have blunted the kidney glucose production and release, since this process is insulin-dependent.

\section{Conclusion}

Total abdominal exenteration for multivisceral transplant in dogs is associated with early major hemodynamics and metabolic changes. The deleterious hemodynamic changes observed after evisceration is probably related with the association of severe acidosis, hyperlactemia, hypoglycemia, and reduction of total circulating blood volume. Close hemodynamic and metabolic monitoring should be provided during experimental multivisceral transplantation in order to promote an increase in successful rates of this complex and challenging procedure.

\section{References}

1. Abu-Elmagd K, Reyes J, Bond G, Mazariegos G, Wu T, Murase N, Sindhi R, Martin D, Colangelo J, Zak M, Janson D, Ezzelarab M, Dvorchik I, Parizhskaya M, Deutsch M, Demetris A, Fung J, Starzl TE. Clinical intestinal transplantation: a decade of experience at a single center. Ann Surg. 2001;234(3):404-16

2. Tzakis AG, Kato T, Levi DM, Defaria W, Selvaggi G, Weppler D, Nishida S, Moon J, Madariaga JR, David AI, Gaynor JJ, Thompson J, Hernandez E, Martinez E, Cantwell GP, Augenstein JS, Gyamfi A, Pretto EA, Dowdy L, Tryphonopoulos P, Ruiz P.100 multivisceral transplants at a single center. Ann Surg. 2005; 242(4):480-90.

3. Starzl TE, Rowe MI, Todo S, et al. Transplantation of multiple abdominal viscera. JAMA. 1989;261.

4. Komokata T, Nishida S, Ogata S, Hamada N, Ikoma A, Tanaka K, Yoshida $\mathrm{H}$, Taira A. Abdominal multivisceral transplantation in pigs. J Hepatobiliary Pancreat Surg. 2000;7(2):188-92.

5. Ai LM, Peng CH, Wu YL, Cao LP, Fang HQ, Liu YB, Peng SY. Orthotopic abdominal multivisceral transplantation without venovenous bypass in pigs. Transplant Proc. 2007;39(1):273-7.

6. Fraczek M, Hevelke P, Kotulski M, S?odkowski M, Kacka A, Wojtasik M, Górnicka B, Korba M, Guzel T, Ziarkiewicz-Wróblewska B, Kalinowski P, Krasnodebski IW, Krawczyk M. Small bowel transplantation-harvesting technique and graft preparation in pigs. Ann Transplant. 2007;12(1):19-26. 7. Jiang F, Yin ZY, Ni XD, Li YS, Li N, Li JS. Modifications in combined liver-small bowel transplantation in pigs. World J Gastroenterol. 2003;9(9):2125-7.

8. Yin ZY, Ni XD, Jiang F, Li N, Li YS, Li JS. Modified technique for combined liver-small bowel transplantation in pigs. World J Gastroenterol. 2003;9(7):1625-8.

9. Yin ZY, Ni XD, Jiang F, Li N, Li YS, Wang XM, Li JS. Auxiliary en-bloc liver-small bowel transplantation with partial pancreas preservation in pigs. World J Gastroenterol. 2004;10(10):1499-503.

10. Galvao FHF, Pompeu E, Mello ES, Costa ACL, Mory E, Santos RM, Santos VR, Machado MC, Bacchella T. Experimental multivisceral transplantation. Xenotransplantation; in press, 2008.

11. Starzl TE, Kaupp HA Jr. Mass homotransplantation of abdominal organs in dogs. Surg Forum. 1960;11:28-30.

12. Cruz RJ Jr, Correia CJ, Ribeiro CM, Poli de Figueiredo LF, Rocha e Silva M.Oxygen consumption, $\mathrm{pCO} 2$ gradients and regional blood flow distribution in an alternative model of intestinal autotransplantation. J Surg Res. 2006;130(1):13-9.

13. Libby P, Maroko PR, Braunwald E.The effect of hypoglycemia on myocardial ischemic injury during acute experimental coronary artery occlusion. Circulation. 1975;51(4):621-6.

14. Teplinsky K, O'Toole M, Olman M, Walley KR, Wood LD. Effect of lactic acidosis on canine hemodynamics and left ventricular function. Am J Physiol. 1990; 258(4 Pt 2):H1193-9.

15. Cruz RJ Jr, Yada-Langui MM, de Figueiredo LF, Sinosaki S, Rocha e Silva M. The synergistic effects of pentoxifylline on systemic and regional perfusion after hemorrhage and hypertonic resuscitation. Anesth Analg. 2006;102(5):1518-24. 
16. Sharma AC, Singh G, Gulati A. Decompensation characterized by decreased perfusion of the heart and brain during hemorrhagic shock: role of endothelin-1. J Trauma. 2002;53(3):531-6.

17. Garrido Adel P, Cruz Junior RJ, Poli de Figueiredo LF, Rocha e Silva M. Small volume of hypertonic saline as the initial fluid replacement in experimental hypodynamic sepsis. Crit Care. 2006;10(2):R62-69.

18. Frühauf NR, Oldhafer KJ, Westermann S, Sotiropoulos GC, Kaiser GM. Acute hepatic failure in swine: hepatectomy versus vascular occlusion. J Invest Surg. 2004;17(3):163-71.

19. Frühauf NR, Oldhafer KJ, Höltje M, Kaiser GM, Frühauf JH, Stavrou GA, Bader A, Broelsch CE. A bioartificial liver support system using primary hepatocytes: a preclinical study in a new porcine hepatectomy model. Surgery. 2004;136(1):47-56.

20. Lee KU, Zheng LX, Cho YB, Kim KH, Ha J, Suh KS, Jung SE. An experimental animal model of fulminant hepatic failure in pigs. J Korean Med Sci. 2005;20(3):427-32.
21. Lauritsen TL, Grunnet N, Rasmussen A, Secher NH, Quistorff B. The effect of hepatectomy on glucose homeostasis in pig and in man.J Hepatol. 2002;36(1):99-104.

22. McGuinness OP, Fugiwara T, Murrell S, Bracy D, Neal D, O'Connor $\mathrm{D}$, Cherrington AD. Impact of chronic stress hormone infusion on hepatic carbohydrate metabolism in the conscious dog. Am J Physiol. 1993;265(2 Pt 1):E314-22.

23. Adrogué HJ. Glucose homeostasis and the kidney. Kidney Int. 1992;42(5):1266-82.

24. Battezzati A, Caumo A, Martino F, Sereni LP, Coppa J, Romito R, Ammatuna M, Regalia E, Matthews DE, Mazzaferro V, Luzi L. Nonhepatic glucose production in humans. Am J Physiol Endocrinol Metab. 2004;286(1):E129-35.

\section{Correspondence:}

Ruy J Cruz Jr, MD PhD

Assistant-Professor, Staff-Surgeon,

Liver, Intestinal and Multivisceral Transplant Services,

Starzl Transplantation Institute Liver, University of Pittsburgh

UPMC Montefiore, 7 south

3459 Fifth Avenue

Pittsburgh, PA 15213-3442

Telephone 1-412-647-5651

Fax 1-412-647-5480

cruzrj@upmc.edu

Received: October 29, 2008

Review: December 10, 2008

Accepted: January 12, 2009

\section{How to cite this article}

Cruz Jr RJ, Garrido AG, Rocha e Silva M. Early hemodynamics and metabolic changes after total abdominal evisceration for experimental multivisceral transplantation. Acta Cir Bras [serial online] 2009 March-April;24(2). Available from: URL: http://www.scielo.br/acb

*Color figure available from www.scielo.br/acb 